\title{
Exploring Chinese EFL Learners' Acquisition Development of Depth of Vocabulary Knowledge Based on Input Corpus and Output Corpus
}

\author{
Xiang Li \\ Department of English \\ Guangdong Police College \\ Guangzhou, China
}

\begin{abstract}
This research makes an empirical study on the longitudinal development of depth of vocabulary Knowledge of Chinese EFL learners from high school to junior period based on textbook corpus TECCL and English writing corpus CLEC. Taking GET as a case study, this study explores its syntagmatic and paradigmatic relations by vertical comparison among different learning stages and horizontal comparison between learner's output and textbook's input. Major findings show that firstly deficient input of depth of vocabulary Knowledge in English textbooks hinders the development of depth of vocabulary Knowledge of Chinese EFL learners, secondly the acquisition of syntagmatic relations lags behind the acquisition of paradigmatic relations, especially lack of knowledge about collocates' semantic preference and semantic prosody, and finally learners do well in mastering the basic or original meaning and relevant colligations and collocations of a polysemic word, but are deficient in the acquisition of other meanings and relevant colligations and collocations.
\end{abstract}

Keywords—depth of vocabulary knowledge; corpus; Chinese learners; syntagmatic relations; paradigmatic relations

\section{INTRODUCTION}

Vocabulary Knowledge is central to Second Language Acquisition and communicative competence and plays a vital role in all language skills (i.e. listening, speaking, reading, and writing) (Schmitt, 2000:55; Nation, 2001). Generally, vocabulary Knowledge is categorized into two types: breadth knowledge and depth knowledge. In the previous researches, two methods are mainly adopted to measure L2 learners' vocabulary knowledge. One is to use vocabulary test such as Vocabulary Levels Test, Productive Levels Test and Vocabulary Knowledge Scale, the other is to measure vocabulary knowledge by analyzing learners' output such as writing, speaking and translation. Since the late 1990s, the researches concerning vocabulary Knowledge in L2 acquisition have shifted from breadth to depth (Zhang, 2006). The researches on depth knowledge can be roughly summarized into the following types: researches on definition of depth of vocabulary knowledge (Palmberg, 1987; Henriksen, 1996; Nation, 1990; Schmitt, 1998), researches on how the depth of vocabulary knowledge is required (Read, 2004; Granger, 2011; Rahimi, 2014), and the influences of the depth of vocabulary knowledge on reading, speaking, translating performance (Qian, 2002; Varnaseri, 2016; Lin, 2015). In China, most relevant researches mainly focus on the influences of the development of Chinese Learners' depth of vocabulary knowledge on reading, writing and comprehensive proficiency and the relationship of depth and breadth knowledge (Lv, 2004; Li, 2007; Zhang, 2006); several studies probe into the longitudinal development of learners' depth of vocabulary knowledge (Tan, 2006, 2007). In addition, He (2015) and Tang (2015) conducted researches on the depth of vocabulary knowledge of English textbooks, which opens a new perspective in this field. However, up to now few empirical researches have been conducted on the longitudinal development of Chinese English learners' depth of vocabulary knowledge based on learner's output corpus. This study is to make a research on the longitudinal development of Chinese learners' depth of vocabulary knowledge from high school to college period based on output corpus and input corpus.

\section{THE DEPTH OF VOCABULARY KNOWLEDGE}

Although there is little controversy on the point that breadth of vocabulary knowledge refers to the quantity or size of vocabulary, and depth of vocabulary knowledge refers to the quality of vocabulary, or how well one knows a word, the connotation of depth of vocabulary knowledge has always been complemented and refined. As a pioneer, Richards (1976) stated that depth of vocabulary knowledge included relative frequency and collocation, limitations on use, syntactic behavior, basic forms and derivations, association with other words, semantic value. Nation (1990) proposed that lexical knowledge consisted of defined form, position, function, and meaning. Qian $(1998,1999)$ refined the previous definition and proposed that depth of vocabulary knowledge included pronunciation, spelling, morphological properties, syntactic properties, meaning, register, and frequency.

Based on the previous definition, this study takes two major dimensions of depth of vocabulary knowledge into consideration, namely, paradigmatic relations (morphology, synonym, antonymy) and syntagmatic relations (collocation, colligation, meaning and function). 


\section{METHOD}

\section{A. Co-selection Theory}

This study applies co-selection theory (Sinclair, 2004) to investigating the lexical acquisition development of Chinese EFL learners because the theory emphasizes that it is not single word but lexical item that constitutes a meaning unit and its work model " $3 \mathrm{C} 2 \mathrm{~S}$ " can explicitly display the syntagmatic dimension of depth of vocabulary knowledge. That is to say, the exploration of syntagmatic relations will start from the word or the core, and then extents to collocation, colligation, semantic preference and semantic prosody. Concretely speaking, this research selects GET(including get, gets, got, getting and gotten) as a case word to explore the acquisition of depth of vocabulary knowledge at different learning stages by comparing the input of depth knowledge of GET in textbooks and the output of depth knowledge of GET in learners' writing. The reason to select GET as a research object is that it is frequently used by learners in different learning stages and its high occurrence frequency can display rich paradigmatic and syntagmatic relations as well as rich co-text, which help uncover different dimensions of depth of vocabulary knowledge (He, 2015; Tang, 2015).

\section{B. Corpus Used in This Research}

Two types of corpora are used in this study. One is output corpus, which is retrieved from Chinese Learner English Corpus, including high school learners' writing (ST2, Tokens 251354, TTR 3.42), freshman's writing (ST3, Tokens 232494, TTR 3.41) and sophomore's writing (ST4, Tokens 241979, TTR 3.66). The other is input corpus, which is retrieved from Pedagogic Colen Corpus, including three sub-corpora: high school textbook (HST) (volume 1-10, Tokens 54558, TTR 12.7), textbook for freshman (TF) (Tokens 362582, TTR 5.4) and textbook for sophomore (TS) (Tokens 405247, TTR 5.5).

\section{RESULTS AND DisCUSSION}

\section{A. Acquisition of GET's Grammatical Structure}

Based on nine grammatical structures of GET summarized by Thornbury (2004:47), this research retrieves all the grammatical structures of GET from target corpora, the results are as follows.

TABLE I. THE OCCURRENCE OF GET'S GRAMMATICAL STRUCTURE IN OUTPUT AND INPUT CORPUS

\begin{tabular}{|c|c|c|c|c|c|c|c|c|}
\hline \multirow{2}{*}{ Type } & \multirow{2}{*}{ meaning } & \multirow{2}{*}{ Grammatical Structure } & \multicolumn{3}{|c|}{ Output Corpus } & \multicolumn{3}{|c|}{ Input Corpus } \\
\hline & & & ST2 & ST3 & ST4 & HST & TF & TS \\
\hline 1 & obtain/receive & GET+ NP & $28 / 67$ & $37 / 226$ & $39 / 210$ & $20 / 29$ & $38 / 101$ & $44 / 92$ \\
\hline 2 & reach & GET + adverbial & $4 / 23$ & $4 / 16$ & $4 / 18$ & $4 / 6$ & $4 / 26$ & $4 / 25$ \\
\hline 3 & \multirow[t]{2}{*}{ become } & GET + adj & $15 / 22$ & $9 / 10$ & $8 / 10$ & $7 / 9$ & $27 / 52$ & $30 / 56$ \\
\hline 4 & & GET + past participle & 0 & $3 / 5$ & $7 / 10$ & $6 / 8$ & $37 / 58$ & $39 / 68$ \\
\hline 5 & manage to do & GET + to-infinitive & $2 / 8$ & $3 / 300$ & $2 / 116$ & $2 / 3$ & $13 / 24$ & $14 / 32$ \\
\hline 6 & give & GET + Pronoun/NP + NP & 0 & 0 & 0 & $1 / 1$ & $3 / 5$ & $3 / 4$ \\
\hline 7 & \multirow[t]{3}{*}{ cause } & GET+ NP + past participle & $2 / 4$ & 0 & $5 / 5$ & $2 / 2$ & $7 / 8$ & $11 / 13$ \\
\hline 8 & & $\begin{array}{l}\text { GET+ pronoun/NP+ to- } \\
\text { infinitive }\end{array}$ & 0 & $1 / 1$ & 0 & $1 / 1$ & $12 / 14$ & $4 / 6$ \\
\hline 9 & & GET + pronoun/NP + V-ing & 0 & 0 & 0 & $1 / 1$ & $2 / 2$ & $4 / 4$ \\
\hline
\end{tabular}

a. Note: the first figure in the table cell refers to the types of GET's collocation word, the second refers to frequency.

"Table I" shows that the first and the third grammatical structures are most frequently used by learners at different learning stages. Consulting different dictionaries, we find that the meaning of "obtain/receive" is always put first of "all "GET vt." entries and "become" is the first entry of all VI entries (Sinclair, 2009; Lu, 2007). Consulting textbooks of junior and senior mid-school, we find that the output order of GET is in line with the order of the first four grammatical structure. Therefore, the first four types of grammatical structures are considered the simple structures of GET, which have been fully acquired by Chinese learners because learners seldom make mistakes in using these structures and the output is relatively rich. Comparing the simple structures, we find that Chinese learners fail to acquire GET's the sixth to ninth structures, namely, complex structures. As Table 1 shows, almost no complex structure appears in HST, and the input of the type and frequency of complex structures are much less than the input of simple structures in TF and TS. Therefore, we boldly conclude that the serious deficiency in the input of complex structures in textbooks results in learners' poor output and acquisition. So far as "GET+toinfinitive" is concerned, although the frequency increases substantially with the development of learning stage, the collocation has no variation and "get to know" almost accounts for $100 \%$ in output corpus. In addition, GET has lost its meaning and becomes grammaticalized. However, there appear a lot of new collocations such as "meet, prove, practice, earn, stop, sympathize, watch, move" in input corpus, which means "manage to achieve something". So we can safely infer that Chinese learners have not acquired this structure.

The results and analyses above expose that Chinese learners have a good command of simple structures, but are seriously deficient in the acquisition of GET's complex grammatical structures, which are important components of GET's depth knowledge. Accordingly, we boldly conclude that Chinese learners' acquisition of depth of vocabulary knowledge is almost stagnant after high school. 


\section{B. Acquisition of GET's Collocates}

Because "GET+ NP" is frequently used by Chinese learners at different learning stages, it is chosen as a sample to investigate the acquisition development of GET's collocates. The retrieved NPs are classified into two types: abstract NP and concrete NP. In ST2, ST3 and ST4, there appear 15, 29 and 32 types of abstract NP respectively; In HST, TF and TS, there are 12, 30 and 37 types respectively.
In addition, with the advancement of learning stage, the number of concrete NPs is decreasing and the number of abstract noun is increasing both in input corpus and in output corpus, which shows that learners' acquisition of GET's collocates is advancing with the development of textbook's input. In order to get a complete picture of the use of "GET+ NP", we retrieve all types of abstract nouns and mark the newly-appeared NP at different learning stages.

TABLE II. The AbStRact Noun COllocates IN “GET+ NP” AT DifFERENT LeARning Stages

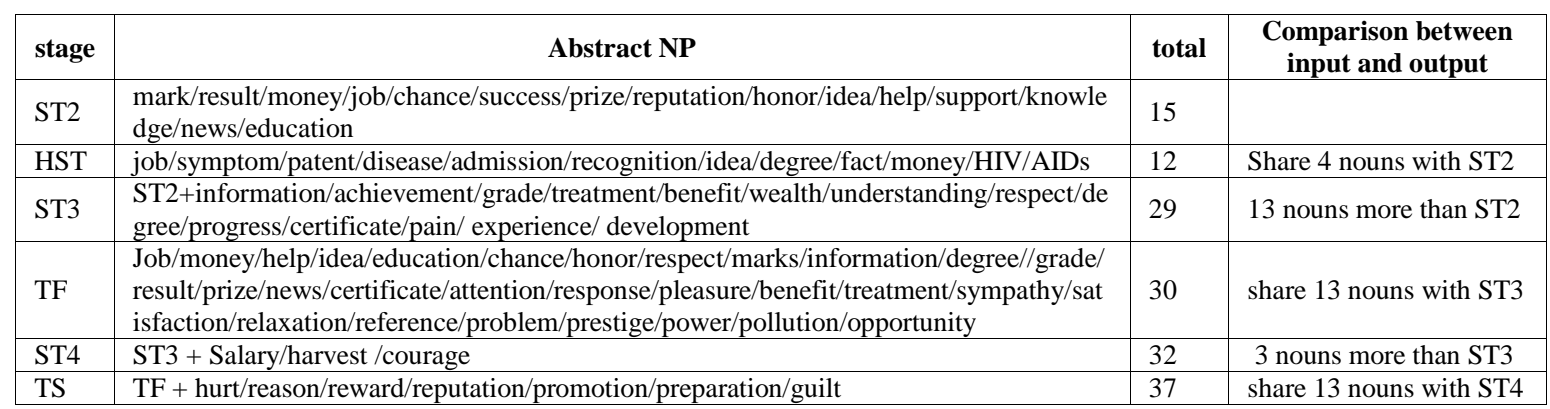

As "Table II" shows, longitudinal comparison exhibits that the types of abstract nouns in "GET+ NP" increase by about $50 \%$ from ST2 to ST3, but only increase by 3 types from ST3 to ST4. Coincidently, the variation tendency of abstract nouns in textbooks of different stages is consistent with the variation of learner's output. Horizontal comparison shows that the abstract nouns are similar in number but different in type between input and output at the same learning stage. In other word, the input has not transformed into output, and learners create many new and different collocates for "GET+ NP". However, consulting COCA, we find that all the new and different collocates are used by native speakers. Therefore, according to the analyses above, we can safely conclude that Chinese learners have a good mastery of GET's collocates in 'GET+ NP".

\section{Acquisition of "GET + Participle"}

TABLE III. TYPES OF "GET + PARTICIPLE” IN INPUT CORPUS AND OUTPUT CORPUS

\begin{tabular}{|l|l|l|l|}
\hline \multicolumn{2}{|c|}{ "GET + particle" in output corpus } & "GET + particle" in input corpus \\
\hline ST2 & $\begin{array}{l}\text { GET up/on/in/into/out/out of/ down/ back/ off/ } \\
\text { to/along/well with/used to/rid of/well on/together }\end{array}$ & HST & ST2 + GET sb out/ hold of/ away \\
\hline ST3 & ST2 + GET over/through/in touch with & TF & ST3 + GET around/by/down \\
\hline ST4 & The same as ST3 & TS & ST4 + GET at/around/by/down \\
\hline
\end{tabular}

"Table III" shows that high school students (ST2) have acquired the majority of "GET + participle" because for one thing only 3 new participles are acquired in ST3 and ST4, for another, most types of "GET + participle" in COLLINS dictionary have been properly used by learners of all stages. Comparing input with output at the same stage, there is little difference in the use of "GET + participle" because although there are more types of "GET + participle" in input than output, these types don't occur frequently in textbooks (frequency< 4). This also proves that low repetition rate usually results in deficient acquisition.

In order to make a further investigation of the acquisition of "GET + participle", we make a case study of "get into" by comparing its collocates between input corpus and output corpus.

TABLE IV. The NOUn COLlOCATES OF “GET INTO” (SPAN=4)

\begin{tabular}{|l|l|l|l|}
\hline & \multicolumn{1}{|c|}{ Physical space } & \multicolumn{1}{c|}{ Abstract space } & \multicolumn{1}{c|}{ other } \\
\hline ST2 & water/pool/bus/shop/house/boat & & \\
\hline ST3 & the end of the floor & society/world/college & age \\
\hline ST4 & & market/university & record book \\
\hline HST & & school & $\begin{array}{l}\text { habit/argument/trouble/files/ } \\
\text { system / hands of police/routine }\end{array}$ \\
\hline TF & $\begin{array}{l}\text { train/corridor/house/bed/car/ } \\
\text { elevator/carriage/canoe/ }\end{array}$ & university/college & $\begin{array}{l}\text { system/work/battle/state/trouble/stock } \\
\text { exchange/ technology }\end{array}$ \\
\hline TS & $\begin{array}{l}\text { train/air/car/bed/kitchen/flying } \\
\text { saucer/taxi/building/bone/blood }\end{array}$ & school/college & \\
\hline
\end{tabular}

As shown in "Table IV", all the noun collocates are semantically categorized into three types: physical space, abstract space and other. The first type collocating with "GET into" means "enter a concrete space"; the second with 
"GET ${ }^{1}$ into" factually expresses "become a member of an organization or community" although "GET into school", "GET into society" and "GET into market", etc. are all translated into Chinese "Jingru"; the third type is miscellaneous and the meaning of "GET into" is deeply influenced by its collocates. For instance, "GET into" means "form" collocating with habit/routine, "participate" with practice/argument/work/battle/technology, "fall into" with trouble/hands of police, "record" with record book/files, etc.

Horizontally contrast exposes that the third type of collocations don't appear in ST2、ST3 and ST4, but are very rich in HST, TF and TS, which means that Chinese learners fail to acquire the third type of collocation. In college stage, the input adds a variety of new collocates, but the new input has not transformed into output, and the first and second type of collocates show no change from high school to college stage, which means that Chinese learners' acquisition of depth knowledge of "GET into" reaches a plateau.

\section{Acquisition of GET's Synonyms}

Read (2004:219) proposed that a way to conceive of depth of vocabulary knowledge is in terms of the building of a lexical network, and depth knowledge can be understood in terms of learner's developing ability to distinguish semantically related words. Based on this idea, this research retrieves all the synonyms of GET with Wordnet Search-3.1 ${ }^{2}$ and calculate the synonyms and their frequency in input corpus and output corpus. Because Chinese learners seldom acquire the complex structures of GET and only the synonym "become" appears in different corpora when GET means "change", we only discuss the synonyms which means "obtain/receive" here.

TABLE V. THE USE OF THE SYNONYMS OF GET (OBTAIN/RECEIVE)

\begin{tabular}{|l|l|l|l|}
\hline & type & $\begin{array}{c}\text { Total } \\
\text { frequency } \\
\text { (standardized } \\
\text { per 10000) }\end{array}$ & \multicolumn{1}{c|}{ Type + frequency } \\
\hline HST & 7 & $53(9.7)$ & $\begin{array}{l}\text { win34, gain 5, receive 6, earn 4, } \\
\text { obtain 1, attain 2, acquire 1 }\end{array}$ \\
\hline ST2 & 4 & $152(6)$ & win 91, receive 37, gain 19, earn 5 \\
\hline TF & 8 & $272(7.5)$ & $\begin{array}{l}\text { receive 100, win 70, earn 38, gain 34, } \\
\text { acquire 18, obtain 7, attain 4, secure 1 }\end{array}$ \\
\hline ST3 & 7 & $160(6.8)$ & $\begin{array}{l}\text { gain 68, win 19, receive 17, earn 18, } \\
\text { acquire 9, attain 3, obtain 26, secure 0 }\end{array}$ \\
\hline TS & 8 & $350(8.6)$ & $\begin{array}{l}\text { receive 111, win 80, earn 38, gain 57, } \\
\text { acquire 22, obtain 25, attain 10, } \\
\text { secure7 }\end{array}$ \\
\hline ST4 & 7 & $257(10.6)$ & $\begin{array}{l}\text { gain 102, earn 37, win 30, receive 25, } \\
\text { acquire 11, attain 17, obtain 35, } \\
\text { secure 0 }\end{array}$ \\
\hline
\end{tabular}

All verb phrases of GET in Chinese high school textbooks are as follows: get up/get to/get on/ get off/ get through/get into/ get sb out/ get out/ get back/get together/get on well with/get along with/get hold of/get away with/get the hang of.

The synonyms retrieved by Wordnet Search-3.1 are gain, acquire, obtain, attain, secure, receive, win, earn.
Longitudinal comparison of the output data in "Table V" finds that there is a big leap from ST2 to ST3 and the frequency of GET's synonyms gradually increases from ST2 to ST3 to ST4 $(6 \rightarrow 6.8 \rightarrow 10.6)$, which means that learners have gradually acquired the paradigmatic relations of GET and have built a complete synonym semantic net around GET. Horizontal comparison exposes that the four synonyms (win, receive, gain, earn) appearing in ST2 are all frequently occurred in HST, and low frequency words (obtain, attain, acquire) in HST don't appear in ST2, which means that at high school stage learners partially acquire the synonyms of GET and low frequency and repetition in textbook lead to failed acquisition. Up to college stage, all the synonyms except "secure" are frequently used by learners, which proves that college learners have almost acquired the synonyms of GET.

In order to figure out how learners use synonyms to replace GET when expressing "obtain/receive", we firstly retrieve all the collocates of GET in "GET + NP" and categorize them into different semantic types, and then retrieve the collocates of each synonym and make a comparison. The semantic types of collocates are as follows. 1) knowledge and skill: education, knowledge, experience, invention, idea, mark, grade; 2) certificate: degree, certificate; 3)information: result, information, answer, conclusion, response/ reply; 4) article: material; 5) misfortune: cancer, illness, pollution, punishment, sentence; 6) profit: benefit, understanding, chance, advice, happiness, love, pleasure, confidence, convenience, satisfaction, feeling, development, access, help, change, independence, control, experience, freedom, qualification, etc.

"Table VI" contains the following information: 1) The type of misfortune collocates doesn't appear in ST2, ST3 and St4 but appears in HST, TF and TS (receive + misfortune), which means that Chinese learners don't think that GET and its synonyms can collocate with nouns expressing misfortune to form negative semantic prosody. This phenomenon signifies that learners don't master semantic prosody, one of syntagmatic relations; 2) Consulting COCA, we find that "earn", "obtain", "win", "gain", "attain", "acquire" are all frequently used to collocate with certificate and degree, but only "gain", "receive", "earn" appear in textbooks and only "gain" and "receive" are used by learners, which shows that insufficient input leads to deficient acquisition; 3) When expressing "GET profit, information and knowledge and skill”, learners' choice of GET's synonyms is similar or even more than that of textbooks, which means that learners have a good mastery of paradigmatic relations. 
TABLE VI. The COLLOCATES OF GET's SynONYMS IN “V+NP”

\begin{tabular}{|l|l|l|l|l|l|l|}
\hline & \multicolumn{1}{|c|}{ knowledge and skill } & certificate & misfortune & \multicolumn{1}{c|}{ information } & \multicolumn{1}{c|}{ article } & \multicolumn{1}{c|}{ profit } \\
\hline ST2 & gain/earn & receive & & gain & receive & receive/gain/earn/win \\
\hline HST & & gain & receive & acquire & receive & gain/receive/earn/attain \\
\hline ST3 & gain/acquire/obtain & gain & & $\begin{array}{l}\text { receive/gain/acquire/att } \\
\text { ain }\end{array}$ & $\begin{array}{l}\text { receive/gain/ } \\
\text { attain/obtain }\end{array}$ & $\begin{array}{l}\text { gain/receive/earn/acquire/attain } \\
\text { /obtain/win }\end{array}$ \\
\hline TF & acquire/obtain/earn & receive/earn & receive & receive/earn & acquire/receive & $\begin{array}{l}\text { gain/win/acquire/attain/obtain/r } \\
\text { eceive/earn }\end{array}$ \\
\hline ST4 & $\begin{array}{l}\text { gain/obtain/acquire/ } \\
\text { attain }\end{array}$ & gain & & receive/ acquire/ obtain & receive & $\begin{array}{l}\text { gain/receive/earn/acquire/ } \\
\text { attain/obtain/win }\end{array}$ \\
\hline TS & gain/obtain/acquire/earn & receive/earn & receive & receive/earn & $\begin{array}{l}\text { acquire/ } \\
\text { receive }\end{array}$ & $\begin{array}{l}\text { gain/win/acquire/attain/ earn } \\
\text { /obtain/receive }\end{array}$ \\
\hline
\end{tabular}

Further investigation into the specific noun collocates of GET's synonyms exposes that the acquisition development of noun collocates is very slow. For example, only "living", "money", "profit" are frequently used to collocate with "earn" from ST2, ST3 to ST4, but in input corpus, the frequently-used collocates of "earn" are very rich, such as "money", "living", "degree", "income", "respect", "points", "credit", "influence”, "profit", "interests", "response”, "fun", etc. Besides, these collocates not only co-occur with "earn" but also with "acquire", "obtain", "attain", "gain". This means that although Chinese learners have gradually built a semantic lexical network on the paradigmatic axis, they don't master well in the syntagmatic relations, especially semantic preference and semantic prosody in the same colligation. One factor contributing to this phenomenon is that learners' selection of collocates is deeply influenced by mother tongue, for instance, "earn money" is the counterpart of Chinese "zhuanqian", "earn living" is equal to Chinese "mousheng".

\section{CONCLUSION}

Taking GET as a case study, this research explores Chinese learners' acquisition development of depth of vocabulary knowledge by investigating GET's syntagmatic and paradigmatic relations. The major findings are as follows:

- The presentation of depth of vocabulary knowledge in textbooks has a big impact on learner's acquisition of depth of vocabulary knowledge. From high school textbooks to college textbooks, insufficient input of GET's complex grammatical structures and collocates results in learner's acquisition failure or deficiency.

- Chinese learners have a good command of the basic or original meaning of a word (the first one or two entries in the dictionary) and its relevant colligations and collocations, but neglect the acquisition of the other meanings of the polysemic word and relevant colligations. The first reason is the deficient input of textbook. The second is that new word acquisition is not based on lexical grammar, so meaning is separated from colligation and collocation. The third reason is that learners pay more attention to the expansion of vocabulary size and think the expansion of breadth of vocabulary knowledge can compensate for the shortage of depth of vocabulary knowledge.
- Chinese learners have a better mastery of paradigmatic relations than syntagmatic relations. They do well in the acquisition of synonyms and "GET + participle" and build easily a semantic lexical network with the development of breadth of vocabulary knowledge, but they perform bad in collocation and colligation. The main reason is that they are unaware of the unity of meaning, structure and function and don't know that the frequent occurrence of collocates sharing similar meaning create semantic preference, let alone semantic prosody.

These findings bring some pedagogical implications for English teaching in China.

- The edition of systematic textbooks should attach more attention to the presentation, development and connection of depth of vocabulary knowledge. After learners have commanded the basic meaning and syntagmatic relations, textbooks ought to provide proper "i+1" syntagmatic and paradigmatic input and design appropriate output tasks in order to promote the development of depth of vocabulary knowledge.

- Teachers should try to foster learners' sense of coselection of lexis, structure, meaning and function. It is effective and feasible for teachers to apply " $3 \mathrm{C} 2 \mathrm{~S}$ " model to lexical teaching, that is, new word teaching can start from morphology to collocation, colligation, semantic preference and semantic prosody.

- Learner's sense of lexical chunks should be strengthened. The promotion of lexical chunk sense can change Chinese learner's separation of structure, meaning and function in vocabulary acquisition. When learners value lexical chunks and take lexical, grammatical and semantic occurrence seriously, their vocabulary knowledge of syntagmatic relations will be substantially improved.

\section{ACKNOWLEDGEMENT}

This research is funded by 2017 Guangdong Social Science Foundation Project (Foreign Language Subject) (GD17WXZ25). 


\section{REFERENCES}

[1] Granger, S. (2011). From Phraseology to Pedagogy: Challenges and Prospects. //T. Herbst, P. Uhrig and S. schuller (eds.), Chunks in the Description of Language. A Tribute to John Sinclair. Berlin \& New York: Mouton de Gruyter, 6.

[2] He, AP. (2015). On Vocabulary development in Streamlined EFL Course Books: A Perspective of Dynamic System Theory. Foreign Language Teaching and Research, 6, 898-908.

[3] Henrisken, B. (1996). Semantisation: A Key Process for Vocabulary Learning and Use[R]. Paper Presented at the 11th AILA World Congress. Finland.

[4] Li, X. (2007). Assessing the Roles of Breadth and Depth of Vocabulary Knowledge in Second Language Proficiency. Foreign Language Teaching and Research, 5, 352-359.

[5] Lin, HF. (2015). Roles of depth of vocabulary knowledge in EFL learner's writing proficiency. PolyU Institutional Research Archive.

[6] Liu, SL. (2001). Exploring Word Knowledge and its Acquisition Patterns: An Experimental Study of Word Meaning and Affix. Foreign Language Teaching and Research, 6, 436-441.

[7] Lu, GS. (2007). English-Chinese Dictionary. Shanghai: Shanghai Translation Publishing House.

[8] Lv, CH. (2004). Vocabulary Size and its Influence on English Achievement as well as its Relationship to Depth of Lexical Knowledge. Foreign Language Teaching and Research, 2, 116-122.

[9] Nation, P. (1990). Teaching and Learning Vocabulary. New York: Newbury House Publishers.

[10] Nation, P. (2001). Learning vocabulary in another language. Cambridge: Cambridge University Press.

[11] Palmberg, R. (1987). Patterns of Vocabulary Development in Foreign Language Learners. Studies in Second Acquisition, 9, 201-220.

[12] Qian, DD. (1998). 'Depth of Vocabulary Knowledge: Assessing its role in Adults' Reading Comprehension in English as a second language'. Ph.D. thesis. University of Toronto.

[13] Qian, D. D. (1999). Assessing the roles of depth and breadth of vocabulary knowledge in reading comprehension. Canadian Modern Language Review, 56, 282-307.

[14] Qian, DD. (2002). Investigating the Relationship Between Vocabulary Knowledge and Academic Reading Performance: An Assessment Perspective. Language Learning, 9.

[15] Rahimi, S. (2014). The effect of vocabulary learning strategy instruction on the depth of vocabulary knowledge. International Journal of Language Learning and Applied Linguistics World, 5.

[16] Read, J. (2004). Plumbing the depths: How should the construct of vocabulary knowledge be defined?. In P. Bogaards \& B. Laufer (eds.) Vocabulary in a Second Language: Selection, Acquisition and Testing. London: Routledge.

[17] Richards, J.C. (1976). The role of vocabulary teaching. TESOL Quarterly, 10, 77-89.

[18] Schmitt, N. (1998). Quantifying word association response: what is native like? System, 26.

[19] Schmitt, N. (2000). Vocabulary in language teaching. Cambridge: Cambridge University Press

[20] Sinclair, J. (2004). Trust the text: Language, corpus and discourse. Routledge.

[21] Sinclair, J. (2009). Collins COBUILD Advanced Dictionary of English. Beijing: Higher Education Press.

[22] Tan, XC. (2006). A Study of Chinese English Learners' Productive Vocabulary Development. Foreign Language Teaching and Research, 3, 202-207.

[23] Tan, XC (2007). A Study of English Learners' Development of Indepth Knowledge on Productive Vocabulary. Foreign Language Education, 3, 52-56.

[24] Tang, JY. (2015). A Corpus-based Study on Depth of Vocabulary Knowledge in College English Textbooks. Higher Education Exploration, 1, 81-86.

[25] Thornbury, S. (2004). Natural Grammar. Oxford: OUP.
[26] Varnaseri, M. (2016). The relationship between depth and breadth vocabulary knowledge and writing performance of Iranian MA students of TEFL. Modern Journal of Language Teaching Methods, 5 .

[27] Zhang, P. (2006). An Overview of Second Language Vocabulary Acquisition Research in China. Foreign Language and Their Teaching, 207, 21-26.

[28] Zhang, XD. (2015). Influence of Lexical Knowledge on L2 Oral Production. Foreign Language World, 4.

[29] Zhang, XB. \& Qiu, TH. (2006) The Relationship between Vocabulary Knowledge and Reading Comprehension. Foreign Language Education, 27(1), 38-41. 